\title{
Recent Trends and Strategies for Targeting M - Cells via Oral Vaccine against Hepatitis B: A Review
}

\author{
Shailesh Jain ${ }^{1}$, Surendra Saraf ${ }^{2 *}$ and Mahendra Kumar Sahu ${ }^{2}$ \\ ${ }^{1}$ Faculty of Pharmacy and Pharmaceutical Sciences, Madhyanchal Professional University, India \\ ${ }^{2}$ Columbia College of Pharmacy Raipur, India
}

Submission: January 18, 2019; Published: February 06, 2019

*Corresponding author: Surendra Saraf, Associate professor, Columbia College of Pharmacy, Tekari, Raipur (C.G.), India

\begin{abstract}
Background: The presence of a mucus layer that covers the surface of a variety of organs has been capitalized to develop mucoadhesive dosage forms that remain in the administration site for more prolonged times, increasing the local and systemic bioavailability of the administered vaccine. The emergence of micro and nanotechnologies together with the implementation of non-invasive and painless administration routes has revolutionized the pharmaceutical market and the treatment of disease.
\end{abstract}

Objectives: To overcome the main drawbacks of the various routes and to maintain patient compliance high, the engineering of innovative drug delivery systems administrable by mucosal routes has come to light and gained the interest of the scientific community due to the possibility to dramatically change the drug pharmacokinetics.

Method: We review herein reported observations on nanoparticle (NP) mediated immunostimulation and immunosuppression, focusing on possible theories regarding how manipulation of particle physicochemical properties can influence their interaction with immune cells to attain desirable immunomodulation and avoid undesirable immunotoxicity.

Result: These results show that both HBV particles and purified HBsAg have an immune modulatory capacity and may directly contribute to the dysfunction of $\mathrm{mDC}$ in patients with chronic HBV. The direct immune regulatory effect of HBV and circulating HBsAg particles on the function of DC can be considered as part of the mechanism by which HBV escapes immunity.

Conclusion: NPs are recognized as self or there is an absence of immune recognition, this represents a major area of interest in the field of drug delivery. It is now well accepted due to their huge advantages and properties such as NP size, surface charge, hydrophobicity/hydrophilicity and the steric effects of particle coating can dictate NP compatibility with the immune system.

Keywords: Hepatitis B Virus (HBV); HBV Infection; Vaccines; Nanoparticles; Oral Mucosal Delivery System

\section{Introduction}

Hepatitis B virus (HBV) infection is the most common chronic viral infection in the world. An estimated 2 billion people have been infected and more than 350 million are chronic carriers of the virus [1]. In the 2018 Global Burden of Disease study, HBV infection ranked in the top health priorities in the world and the tenth leading cause of death $(7,86000$ deaths per year). These data have led WHO to include viral hepatitis in its major public health priorities. HBV is transmitted through contact with infected blood or semen [2,3]. Three major modes of transmission prevail. In areas of high endemicity, HBV is transmitted mostly perinatally from infected mothers to neonates, in low endemic areas, sexual transmission is predominant and third major source of infection is unsafe injections, blood transfusions or dialysis. HBV belongs to the Hepadnaviridae family. It is a partly double stranded DNA virus with approximately 3200 base pairs. The transcriptional template of HBV is the cccDNA, which resides inside the hepatocyte nucleus as a mini-chromosome.
The maintenance of covalently closed circular DNA (cccDNA) is essential for the persistence of the virus $[4,5]$.

The replication of HBV implicates reverse transcription of the pregenomic RNA intermediate into HBV DNA. Reverse transcriptase is error prone and the mutation rate is high (appendix). The receptor for HBV entry into hepatocytes is sodium taurocholate polypeptide [6]. These mutations abolish or down regulate the production of $\mathrm{HBeAg}$ without affecting the replication capacity of the virus and cause HBeAg negative chronic HBV infection. The precore and basal core promoter mutations can occur alone or together. HBV infection can be prevented by avoiding transmission from infected people and by inducing immunity in unexposed people. A safe and effective vaccine has been available since 1982, introduction of HBV vaccine led to a decrease in the incidence of not only HBV infection but also hepatocellular carcinoma [7,8]. Most experience available to date comes from using two recombinant 
vaccines like Engerix-B (SmithKline Biologicals, Belgium) and RECOMBIVAX HB-Vax II (Merck \& Co., USA). Admministered via different routes such as Pulmonary, Nasal, Intravenous (IV), Intramuscular (IM), Subcutaneous and Oral mucosal (OM) in the form of dried powder, liquid along with nanoparticles (NPs) [9]. Among of all DS NPs offers many potential advantages e.g. large surface area, site-specific delivery of drugs, peptides and genes, improved in vitro, in vivo stability and reduced side effect profile. However, NPs are often first picked up by the phagocytic cells of the immune system (e.g. macrophages), there may be undesirable interactions between NPs and the immune system whenever given via OM. Aim of the present study was to assess advantages of NPs and OM delivery system (DS) in comparison to the other formulation and site of administration [10].

\section{Nps As Potential Delivery System of Vaccine}

NPs interact with the immune system and effects on the immune cells may benefit treatment of disorders mediated by unwanted immune responses and enhance immune response to weak antigens [11-13]. On the other hand, undesirable immunostimulation or immunosuppression by NPs may result in safety concerns and should be minimized. One of the few studies on immunosuppression has demonstrated that inhalation of CNTs suppresses B cell function and that the TGF- produced by alveolar macrophages is a key element in the mechanism of the observed immunosuppression. Other studies have shown that NPs can be used to deliver immunosuppressive drugs and prevent immunosuppressive properties of small-molecule drugs. Similarly, allergen-loaded PLGA, chitosan, poly (lactic acid), poly (methyl vinyl ether-co-maleic anhydride) NPs, and dendrosomes have been reported as effective suppressors [14,15]. NPs are also evaluated for their immunostimulatory potential based on their ability to stimulate innate or adaptive immune responses. NP immunogenicity is drawing interest because NPs have been shown to improve antigenicity of conjugated weak antigens and thus serve as adjuvants because some NPs have been shown to be antigenic themselves. The former property has been shown to depend on particle size, surface charge and significantly contribute to the development of improved vaccine formulations [16]. Particle size has been reported as a major factor in determining whether antigens loaded into NPs induce type I (interferon) or type II (IL-4) cytokines, thereby contributing to the type of immune response [17]. A leading hypothesis on why nanotechnology formulations (Polymeric NPs, Nanoliposomes, Solid Lipid NPs (SLNs), Nanoemulsions) are effective in vaccine development is that nonsoluble NPs provide controlled, slow release of antigens, creating a depot at the site of injection and providing protection in the destabilizing in vivo environment $[18,19]$.

\section{M-Cell Targeted Mucosal Vaccine and Transport Mechanism Across the Intestinal Mucosa}

Literature surveys were suggested that exploiting the potential of M-cell-specific mechanisms for drug and vaccine delivery to the mucosal immune system. Many M-cell-targeted molecules have been used for development of mucosal vaccines [20-23].

\section{M-cell-specific molecules in mucosal vaccine development}

M cells express a large amount of immune-surveillance receptors on the apical surfaces, contributing to the variety of microbial pathogens and antigens [24]. They are provided with an array of molecules to present luminal antigens to the underlying mucosal lymphoid tissues. Therefore, identifying M-cell-specific targeting molecules has been a focus, by recognizing molecules exploited by pathogens to invade M cells [25-27].

\section{Glycoprotein 2 (GP2)}

GP2 is specially expressed on M cells; this protein is highly expressed on the apical membranes of Peyer's Patch (PP) M cells, but not highly expressed on other enterocyte populations [28]. Recent studies have revealed that GP2 acts as a transcytotic receptor, bound to FimH+ bacteria such as Escherichia coli and S. Typhmurium, by recognizing FimH, a major component of the type 1 pilus on the outer membrane of a subset of Gramnegative enterobacilli $[29,30]$. Thus, GP2 on M cells can act as a transcytotic receptor for bacterial antigens, and worthy of note, participate in the mucosal immune responses to these particular bacteria; a subset of commensal and pathogenic enterobacteria (E. coli and S. Typhmurium) [31-33]. Other research has shown that a murine GP2 (mGP2)-specific aptamer, isolated using Systematic evolution of ligands by exponential enrichment (SELEX), with a loop structure and the nucleotide sequence, AAAUA (both important for binding to mGP2), binds to mGP2 expressed on the cell surface, indicating that the aptamer serves as a promising tool for testing M-cell-targeted vaccine delivery in murine model systems [34].

\section{Cellular Prion Protein $\left(\operatorname{PrP}^{\mathrm{C}}\right)$}

$\operatorname{PrP}^{\mathrm{C}}$ is highly expressed on the luminal side of the apical plasma membrane of murine M cells and co-localized with GP2, suggesting that it is an antigen receptor candidate on $\mathrm{M}$ cells [3436]. $\mathrm{PrP}^{\mathrm{C}}$ interacts with heat shock protein (Hsp) of B. abortus, which had been recognized as an immunodominant antigen of many microbes. Accumulated evidence suggests that PrPC on $\mathrm{M}$ cells is well placed to contribute to mucosal immunosurveillance by enhancing transcytosis of B. abortus or other exogenous antigens [37-39].

\section{C5a Receptor (C5aR)}

The expression and nonredundant role of C5aR in human M-like cells and mouse $M$ cells have been demonstrated, indicating the role of $\mathrm{C} 5 \mathrm{aR}$ as a target receptor to induce the immune response [40]. Sae-Hae Kim et al. verified phosphorylation of $\mathrm{C} 5 \mathrm{aR}$ in vivo after oral infection of mice by Yersinia enterocolitica. They confirmed the expression of $\mathrm{C} 5 \mathrm{aR}$ in the apical area of mouse $\mathrm{M}$ cells and human M-like cells by 
measuring the expression levels of mRNA and protein [4143]. Sae-Hae Kim et al. also used the outer membrane protein $\mathrm{H}(\mathrm{OmpH})$ ligand of Yersinia enterocolitica, which acts as a targeting ligand to $\mathrm{C} 5 \mathrm{aR}$ in $\mathrm{M}$ cells, to induce specific mucosal and systemic immunity against envelope domain III (EDIII) of dengue virus (DENV), suggesting $\mathrm{OmpH}$ - mediated targeting of antigens to $\mathrm{M}$ cells as an efficient oral vaccination against DENV infection [44].

\section{Other specific molecules}

There are other M-cell-specific molecules that may specifically bind to components of potential pathogenic organisms [45]. Peptidoglycan recognition protein 1 is an innate recognition protein binding to bacterial peptidoglycan and is also expressed highly in M cells53. Annexin (ANX) A5 expressed by $M$ cells can bind to lipopolysaccharide (LPS) of Gramnegative bacteria and block endotoxin activity, suggesting that ANXA5 on M cells acts as an uptake receptor for Gram-negative bacteria [45]. The discovery of M-cell-targeting receptors using pathogen-exploited molecules could be a promising approach in the development of effective mucosal vaccines. Clusterin, fatty acid binding protein, cathepsin E, secretogranin $\mathrm{V}$ and other $\mathrm{M}$-cell-expressed proteins may have potential roles in $\mathrm{M}$ cell functions, but these are less clearly understood [46-47]. The increasing evidences have demonstrated that M-cell-specific molecular antibody, which is conjugated with antigen protein or liver vector, can transport the antigen to mucosal tissues, leading to produce efficient immune responses [48]. However, some molecules, selected as M-cell-specific molecules, are not uniquely expressed on M cells, resulting in producing a non-ideal oral delivery system for targeting $\mathrm{M}$ cells. With the development research on the mechanism of $M$ cell differentiation, we can regulate the immune processes by means of artificial mediation of the M-cell-specific molecules gene expression [49,50]. For instance, we can increase the efficiency of mucosal vaccination, through booting the expression of certain M-cell-specific molecules. Meanwhile, we can even inhibit the viral infection, by reducing the expression of some molecules, which are necessary for the entry of some virus particles [51].

\section{$M$ cell ligands as novel and effective mucosal vaccine targets}

Many researchers have studied $M$ cell ligands, in order to take advantage of the fact that targeting specific receptors on the apical membrane of $\mathrm{M}$ cells could specifically increase antigen uptake and presentation, evoking immune responses and providing protection against Infection $[52,53]$.

\section{NKM 16-2-4}

NKM 16-2-4 can be used as monoclonal antibody to target vaccine antigens to the M-cell-specific carbohydrate moiety [54]. It can distinguish $\alpha$ [1,2]- fucosylated M cells from goblet cells containing abundant sialic acids neighboring the $\alpha[1,2]$ fucose moiety and from non- $\alpha[1,2]$ - fucosylated epithelial cells $[55,56]$. The use of NKM 16-2-4 targeting vaccine antigens to M cells could be effective for vaccine delivery into the intestinal mucosa. Oral vaccination using antigen-encapsulated liposomes coupled with UEA-1 could lead to increased uptake by PP M cells and the induction of higher antigen specific sIgA responses [57].

\section{Co1 ligand}

Many studies have investigated the M-cell-targeting ligand, Co1, selected from a phage display library against differentiated M-like cells, and have produced recombinant antigen fused to the selected ligands using the model antigen [58]. Co1 ligand promotes the uptake of fused antigen and enhances the immune response against the fused antigen, indicating that Co1 could be used as an adjuvant for targeted antigen delivery into the mucosal immune system to enhance immune induction [59]. Another promising approach used Co1 ligand to induce specific immune responses against a pathogenic viral antigen, EDIII of DENV. Efficient antigen delivery into PPs was observed and the antibodies induced by the Co1-ligand-conjugated EDIII antigen showed effective virus-neutralizing activity. Taken together, these results reveal that M-cell-targeting ligands with adjuvant activity can be designed to exploit our knowledge of receptors expressed on the apical surface of $M$ cells involved in pathogen invasion $[60,61]$.

\section{Caveolin-1}

Caveolin-1 is the major structural component of caveolae. It was examined its expression in Caco-2-driven M-like cells, and was verified that co-culturing with B lymphocytes, caveolin-1 could increase the susceptibility of $\mathrm{M}$ cells to Salmonella infection. Some recent studies have shown that caveolin-1 is not only a good marker of human $\mathrm{M}$ cells, but also a potent candidate for understanding $\mathrm{M}$ cell transcytosis as a novel target for mucosal immunity [62].

\section{Ulex europaeus agglutinin (UEA)-1}

UEA-1 has been confirmed as a specific ligand for $\alpha$-Lfucose present on the apical membrane of M cells, anchored for selective delivery of antigen to GALT. Some researchers have used NPs coated by UEA-1-conjugated alginate to induce immunological response in BALB/c mice and compared them with aluminum hydroxide gel-based conventional vaccine [63]. The results demonstrated that immunization with the former induced efficient systemic as well as mucosal immune responses against BSA compared to other formulations, which indicated the potential of UEA-alginate-coated NPs as an effective oral delivery system. However, UEA-1 lectin also reacted strongly with other issues, such as goblet cells and the mucus layer covering the intestinal epithelium [64]

\section{Reovirus surface protein $\alpha 1$ (p $\alpha 1)$}

p 1 has the ability to bind M cells, which facilitates reovirus infection via p $\alpha 1$. A genetic fusion between ovalbumin (OVA) and $p \alpha 1$ was applied nasally, to enhance tolerogen uptake [65]. Studies showed that OVA- pa1-mediated tolerance was lost in 
the absence of interleukin-10, demonstrating that the feasibility of using p $\alpha 1$ as a mucosal delivery platform specifically for low-dose tolerance induction. Another targeted transgene vaccination using p $\alpha 1$ conjugated to polylysine through intranasal immunization, could induce mucosal immunity and enhance cell-mediated immunity, leading to prolong mucosal IgA and produce antigen-specific serum IgG [66].

The number of $\mathrm{M}$ cell receptors and their ligands that have been identified so far is limited, and most of them are not just expressed in M cells, but in neighboring enterocytes as well. Tolllike receptor (TLR)- 4 and $\alpha 5 \beta 1$ integrin, belonging to pathogen recognition receptors (PRRs), are expressed on the surface of human and mouse $M$ cells [67]. Interaction between these innate immune system molecules with pathogen-associated molecular patterns is essential for bacteria translocation across the lumen. Nevertheless, PRRs are also expressed in other enterocytes and not merely in $\mathrm{M}$ cells. For example, $\alpha 5 \beta 1$ integrin is both dispersed on the lateral and basolateral surfaces of enterocytes and on the apical surface of $M$ cells, which is a challenge in targeting M cells alone [68].

M-cell-targeting ligands can enhance the uptake of oral vaccines by $M$ cells and improve antigen-specific immune responses in both mucosal and systemic immunity. It seems that targeting ligand to antigen is a very promising approach in the development of efficient mucosal vaccine. However, simple targeting of antigen to $\mathrm{M}$ cells does not ensure the production of efficient protective immunity. We should pay more attention to the ligand study and find out the "optimal transporter", presenting antigens to $M$ cells, leading to efficient immune responses [69].

\section{Immune-Olerance}

The antibody response to HBV - envelope antigens (HBsAg) is a T-cell dependent process.6 Antibodies to HBsAg serve as neutralising agent. These neutralising antibodies are especially important in the prevention of viral infection, since they could prevent viral attachment and entry into the cells by absorption of the viral particles. Induction of anti-HBs alone during prophylactic vaccination is often sufficient to completely prevent viral infection, irrespective of whether this is the only operative defence mechanism against the viral infection during the course of natural infection [70]. The antibody is detectable in patients who have recovered from acute hepatitis B and in people immunised with HBV vaccine, but it could become undetectable in patients who have recovered fully from infection. Antibody to HBcAg (Hepatitis B core antigen) is detected in virtually all patients who have ever been exposed to HBV. Unlike antibody to HBsAg this antibody is not protective; its presence alone cannot be used to distinguish acute from chronic infection [71].

The HBV-specific T-cell and B-cell responses are generally undetectable. The exact mechanism by which HBV escapes immunity is still not known. Dendritic Cells (DC) play an important role in antiviral immunity and have the unique capacity to activate naive $\mathrm{T}$ cells and stimulate $\mathrm{B}$ and natural killer cells. Both circulating and tissue-resident immature DC sample the environment for the presence of foreign antigens and upon activation, DC migrate to lymphoid tissues to initiate immune responses [72]. Depending on their maturation status, represented by the expression level of costimulatory and Human Leucocyte Antigen (HLA) molecules and the capacity to produce proinflammatory cytokines, DC can induce either immunity or tolerance. Immature and semi-mature DC are associated with tolerogenic responses, so in the context of HBV a defect in the maturation process of DC may lead to tolerogenic T-cell responses and HBV persistence [73].

\section{Conclusion}

In summary, existing studies have demonstrated that nanotechnology offers many advantages, such as improved stability, favourable biodistribution profiles, slower drug release kinetics, lower immunotoxicity, and targeting to specific cell populations [74]. Lessons learned from previous studies include the importance of detection and prevention of potential particle contamination with such things as bacterial endotoxins and/or toxic synthesis by-products, and the importance of understanding how route of administration and particle biodistribution in the body may result in either desirable and undesirable immunomodulation (e.g. complement activation on IV and SC administration is not desirable, whereas on OM administration, it is beneficial for vaccinations) [75]. Nanotechnology platforms are being investigated as vaccine carriers, adjuvants, and drug delivery systems to target inflammatory and inflammationassociated disorders. Some formulations are already in clinical trials, whereas many others are in various phases of preclinical development. Although in recent years, our understanding of NPs interaction with components of the immune system has improved, many questions still require more thorough investigation and deeper understanding. Further mechanistic studies investigating particle immunomodulatory effects (immunostimulatory and immunosuppression) are required to improve our understanding of the physicochemical parameters of NPs that define their effects on the immune system [76,77].

\section{References}

1. Jamil A, Hamid S, Aziz Q (2018) Prevalence of Hepatitis B Among Pregnant Women. Journal of Islamabad Medical \& Dental College 7(2): 128131.

2. Jefferies M, Rauff B, Rashid H, Lam T, Rafiq S (2018) Update on global epidemiology of viral hepatitis and preventive strategies. World $\mathrm{j}$ clin cases 6(13): 589-599.

3. Ambachew H, Zheng M, Pappoe F, Shen J, Xu Y (2018) Genotyping and sero-virological characterization of hepatitis B virus (HBV) in blood donors, Southern Ethiopia. PloS one13(2): e0193177.

4. Ioannou GN (2011) Hepatitis B virus in the United States: infection, exposure, and immunity rates in a nationally representative survey. Annals of internal medicine 154(5): 319-328.

5. Luo Z, Li L, Ruan B (2012) Impact of the implementation of a vaccination strategy on hepatitis B virus infections in China over a 20-year period. International Journal of Infectious Diseases 16(2): e82-e88. 
6. Araujo NM, Waizbort R, Kay A (2011) Hepatitis B virus infection from an evolutionary point of view: how viral, host, and environmental factors shape genotypes and subgenotypes. Infection, Genetics and Evolution 11(6): 199-207.

7. Lavanchy D (2004) Hepatitis B virus epidemiology, disease burden, treatment, and current and emerging prevention and control measures. Journal of viral hepatitis 11(2): 97-107.

8. Kao JH, Chen DS (2002) Global control of hepatitis B virus infection. The Lancet infectious diseases 2(7): 395-403.

9. Trépo C, Chan HL, Lok A (2014) Hepatitis B virus infection. The Lancet 384(9959): 2053-2063.

10. Liaw YF, Chu CM (2009) Hepatitis B virus infection. The lancet 373(9663): 582-592.

11. Mahapatro A, Singh DK (2011) Biodegradable nanoparticles are excellent vehicle for site directed in-vivo delivery of drugs and vaccines. Journal of nanobiotechnology 9(1): 55 .

12. Honary S, Zahir F (2013) Effect of zeta potential on the properties of nano-drug delivery systems-a review (Part 1). Tropical Journal of Pharmaceutical Research 12(2): 255-264.

13. Huh AJ, Kwon YJ (2011) Nanoantibiotics: a new paradigm for treating infectious diseases using nanomaterials in the antibiotics resistant era. Journal of controlled release 156(2): 128-145.

14. Sarei F, Dounighi NM, Zolfagharian H, Khaki P, Bidhendi SM (2013) Alginate nanoparticles as a promising adjuvant and vaccine delivery system. Indian journal of pharmaceutical sciences 75(4): 442.

15. Ferreira SA, Gama FM, Vilanova M (2013) Polymeric nanogels as vaccine delivery systems. Nanomedicine: Nanotechnology, Biology and Medicine 9(2): 159-173.

16. Jia F, Liu X, Li L, Mallapragada S, Narasimhan B, Wang Q (2013) Multifunctional nanoparticles for targeted delivery of immune activating and cancer therapeutic agents. Journal of Controlled Release 172(3): $1020-1034$

17. Gregory AE, Williamson D, Titball R (2013) Vaccine delivery using nanoparticles. Frontiers in cellular and infection microbiology 3: 13 .

18. Leleux J, Roy K (2013) Micro and nanoparticle-based delivery systems for vaccine immunotherapy: an immunological and materials perspective. Advanced healthcare materials 2(1): 72-94.

19. Akagi T, Baba M, Akashi M (2011) Biodegradable nanoparticles as vaccine adjuvants and delivery systems: regulation of immune responses by nanoparticle-based vaccine. In Polymers in nanomedicine: 31-64.

20. Cruz LJ, Tacken PJ, Fokkink R, Figdor CG (2011) The influence of PEG chain length and targeting moiety on antibody-mediated delivery of nanoparticle vaccines to human dendritic cells. Biomaterials 32(28): 6791-6803

21. Sarti F, Perera G, Hintzen F, Kotti K, Karageorgiou V, Kammona O, et al. (2011) In vivo evidence of oral vaccination with PLGA nanoparticles containing the immunostimulant monophosphoryl lipid A. Biomaterials 32(16): 4052-4057.

22. Bolhassani A, Javanzad S, Saleh T, Hashemi M, Aghasadeghi MR, et al (2014) Polymeric nanoparticles: potent vectors for vaccine delivery targeting cancer and infectious diseases. Human vaccines \& immunotherapeutics 10(2): 321-332.

23. Silva JM, Videira M, Gaspar R, Préat V, Florindo HF (2013) Immune system targeting by biodegradable nanoparticles for cancer vaccines. Journal of Controlled Release 168(2): 179-199.

24. Krishnamachari Y, Geary SM, Lemke CD, Salem AK (2011) Nanoparticle delivery systems in cancer vaccines. Pharmaceutical research 28(2): 215-236.
25. Ganguly K, Chaturvedi K, More UA, Nadagouda MN, Aminabhavi TM (2014) Polysaccharide-based micro/nanohydrogels for delivering macromolecular therapeutics. Journal of Controlled Release 193:162173.

26. Beija M, Salvayre R, Lauth de Viguerie N, Marty JD (2012) Colloidal systems for drug delivery: from design to therapy. Trends in biotechnology 30(9): 485-496.

27. Blecher K, Nasir A, Friedman A (2011) The growing role of nanotechnology in combating infectious disease. Virulence 2(5): 395-401.

28. Hussain S, Vanoirbeek JA, Hoet PH (2012) Interactions of nanomaterials with the immune system. Wiley Interdisciplinary Reviews: Nanomedicine and Nanobiotechnology 4(2): 169-183.

29. Liu Z, Lv D, Liu S, Gong J, Wang D, et al. (2013) Alginic acid-coated chitosan nanoparticles loaded with legumain DNA vaccine: effect against breast cancer in mice. PLoS One 8(4): e60190.

30. Hu Y, Ehrich M, Fuhrman K, Zhang C (2014) In vitro performance of lipid-PLGA hybrid nanoparticles as an antigen delivery system: lipid composition matters. Nanoscale research letters 9(1): 434.

31. Zhao K, Zhang Y, Zhang X, Shi C, Wang X, et al. (2014) Chitosan-coated poly (lactic-co-glycolic) acid nanoparticles as an efficient delivery system for Newcastle disease virus DNA vaccine. International journal of nanomedicine 9: 4609.

32. Kesharwani P, Jain K, Jain NK (2014) Dendrimer as nanocarrier for drug delivery. Progress in Polymer Science 39(2): 268-307.

33. Alonso MJ, Csaba NS (2012) Nanostructured biomaterials for overcoming biological barriers. Royal Society of Chemistry.

34. Rana S, Bajaj A, Mout R, Rotello VM (2012) Monolayer coated gold nanoparticles for delivery applications. Advanced drug delivery reviews 64(2): 200-216.

35. Yun Y, Cho YW, Park K (2013) Nanoparticles for oral delivery: targeted nanoparticles with peptidic ligands for oral protein delivery. Advanced drug delivery reviews 65(6): 822-832.

36. Plapied L, Duhem N, Des Rieux A, Préat V (2011) Fate of polymeric nanocarriers for oral drug delivery. Current opinion in colloid \& interface science 16(3): 228-237.

37. Devriendt B, De Geest BG, Goddeeris BM, Cox E (2012) Crossing the barrier: Targeting epithelial receptors for enhanced oral vaccine delivery. Journal of controlled release 160(3): 431-439.

38. Chen MC, Mi FL, Liao ZX, Hsiao CW, Sonaje K, et al. (2013) Recent advances in chitosan-based nanoparticles for oral delivery of macromolecules. Advanced drug delivery reviews 65(6): 865-879.

39. Mabbott NA, Donaldson DS, Ohno H, Williams IR, Mahajan A (2013) Microfold (M) cells: important immunosurveillance posts in the intestinal epithelium. Mucosal immunology 6(4): 666-677.

40. Woodrow KA, Bennett KM, Lo DD (2012) Mucosal vaccine design and delivery. Annual review of biomedical engineering 14: 17-46.

41. Mantis NJ, Rol N, Corthésy B (2011) Secretory IgA's complex roles in immunity and mucosal homeostasis in the gut. Mucosal immunology 4(6): 603-611.

42. Schulz O, Pabst 0 (2013) Antigen sampling in the small intestine. Trends in immunology 34(4): 155-161.

43. Yamamoto M, Pascual DW, Kiyono H (2011) M cell-targeted mucosal vaccine strategies. In Mucosal Vaccines: 39-52.

44. Lawson LB, Norton EB, Clements JD (2011) Defending the mucosa: adjuvant and carrier formulations for mucosal immunity. Current opinion in immunology 23(3): 414-420. 
45. Peterson LW, Artis D (2014) Intestinal epithelial cells: regulators of barrier function and immune homeostasis. Nature Reviews Immunology $14(3): 141-153$.

46. Trevaskis NL, Kaminskas LM, Porter CJ (2015) From sewer to saviour-targeting the lymphatic system to promote drug exposure and activity. Nature Reviews Drug Discovery 14(11): 781-803.

47. Kim SH, Lee KY, Jang YS (2012) Mucosal immune system and M cell-targeting strategies for oral mucosal vaccination. Immune network 12(5): 165-175.

48. Irvine DJ, Swartz MA, Szeto GL. Engineering synthetic vaccines using cues from natural immunity. Nature materials. 2013 Nov;12(11):978990.

49. Lycke N. Recent progress in mucosal vaccine development: potential and limitations. Nature Reviews Immunology. 2012 Aug;12(8):592605

50. Lelouard H, Fallet M, De Bovis B, Méresse S, Gorvel JP (2012) Peyer's patch dendritic cells sample antigens by extending dendrites through M cell-specific transcellular pores. Gastroenterology 142(3): 592-601.

51. O’Neill MJ, Bourre L, Melgar S, O’Driscoll CM (2011) Intestinal delivery of non-viral gene therapeutics: physiological barriers and preclinical models. Drug discovery today 16(5-6): 203-218.

52. Castro Sánchez P, Martín Villa JM (2013) Gut immune system and oral tolerance. British Journal of Nutrition 109(S2): S3-S11.

53. Ye T, Yue Y, Fan X, Dong C, Xu W, Xiong S (2014) M cell-targeting strategy facilitates mucosal immune response and enhances protection against CVB3-induced viral myocarditis elicited by chitosan-DNA vaccine. Vaccine 32(35): 4457-4465

54. McGhee JR, Fujihashi K (2012) Inside the mucosal immune system. PLoS biology 10(9): e1001397.

55. Ogra PL, Mestecky J, Lamm ME, Strober W, McGhee JR (2012) Handbook of mucosal immunology. Academic Press.

56. Pascual DW, Fujihashi K, Maddaloni M (2011) Inventors; Montana State University, University of Alabama at Birmingham Research Foundation, assignee. Tolerizing agents. United States patent application US $13 / 027,805$.

57. Armand P, Nagler A, Weller EA, Devine SM, Avigan DE, et al. (2013) Disabling immune tolerance by programmed death-1 blockade with pidilizumab after autologous hematopoietic stem-cell transplantation for diffuse large B-cell lymphoma: results of an international phase II trial. Journal of clinical oncology 31(33): 4199-4206.

58. Akdis M, Akdis CA (2014) Mechanisms of allergen-specific immunotherapy: multiple suppressor factors at work in immune tolerance to allergens. Journal of Allergy and Clinical Immunology 133(3): 621-631.

59. Bilate AM, Lafaille JJ (2012) Induced CD4+ Foxp3+ regulatory T cells in immune tolerance. Annual review of immunology 30:733-758.

60. Shouval DS, Biswas A, Goettel JA, McCann K, Conaway E, et al. (2014) Interleukin-10 receptor signaling in innate immune cells regulates mucosal immune tolerance and anti-inflammatory macrophage function. Immunity 40(5): 706-719.

61. Ali K, Soond DR, Piñeiro R, Hagemann T, Pearce W, et al. (2014) Inactivation of PI (3) K p110 $\delta$ breaks regulatory T-cell-mediated immune tolerance to cancer. Nature 510(7505): 407-411.
62. Messinger YH, Mendelsohn NJ, Rhead W, Dimmock D, Hershkovitz E, et al. (2012) Successful immune tolerance induction to enzyme replacement therapy in CRIM-negative infantile Pompe disease. Genetics in medicine 14(1):135-142.

63. Owen JA, Punt J, Stranford SA (2013) Kuby immunology. New York: WH Freeman.

64. Rivera Gil P, Jimenez De Aberasturi D, Wulf V, Pelaz B, et al. (2012) The challenge to relate the physicochemical properties of colloidal nanoparticles to their cytotoxicity. Accounts of chemical research 46(3): 743-749.

65. Hajipour MJ, Fromm KM, Ashkarran AA, De Aberasturi DJ, De Larramendi IR, et al. (2012) Antibacterial properties of nanoparticles. Trends in biotechnology 30(10): 499-511.

66. Laurent S, Burtea C, Thirifays C, Häfeli UO, Mahmoudi M (2012) Crucial ignored parameters on nanotoxicology: the importance of toxicity assay modifications and "cell vision". PloS one 7(1): e29997.

67. Tenzer S, Docter D, Rosfa S, Wlodarski A, Kuharev J, et al. (2011) Nanoparticle size is a critical physicochemical determinant of the human blood plasma corona: a comprehensive quantitative proteomic analysis. ACS nano 5(9): 7155-7167.

68. Xiao K, Li Y, Luo J, Lee JS, Xiao W, et al. (2011) The effect of surface charge on in vivo biodistribution of PEG-oligocholic acid based micellar nanoparticles. Biomaterials 32(13): 3435-3446.

69. Bertrand N, Wu J, Xu X, Kamaly N, Farokhzad OC (2014) Cancer nanotechnology: the impact of passive and active targeting in the era of modern cancer biology. Advanced drug delivery reviews 66: 2-5.

70. Lesniak A, Salvati A, Santos Martinez MJ, Radomski MW, Dawson KA, et al. (2013) Nanoparticle adhesion to the cell membrane and its effect on nanoparticle uptake efficiency. Journal of the American Chemical Society 135(4): 1438-1444.

71. Zhu M, Nie G, Meng H, Xia T, Nel A, at al. (2012) Physicochemical properties determine nanomaterial cellular uptake, transport, and fate. Accounts of chemical research 46(3): 622-631.

72. El Sayed A, Kamel M (2018) Advanced applications of nanotechnology in veterinary medicine. Environmental Science and Pollution Research 13: $1-4$.

73. Roy K (2018) ImmunoEngineering and Cell Manufacturing: The Next Frontiers in Biomedical Nano/Microtechnologies.

74. Wei C, Dong X, Liang J, Zhang Y, Zhu D, et al. (2019) Real-Time Imaging Tracking of a Dual Fluorescent Vaccine Delivery System Based on Ovalbumin Loaded Zinc Phthalocyanine-Incorporated Copolymer Nanoparticles. Journal of biomedical nanotechnology 15(1): 100-112.

75. Bai DP, Lin XY, Huang YF, Zhang XF (2018) Theranostics Aspects of Various Nanoparticles in Veterinary Medicine. International journal of molecular sciences 19(11): 3299.

76. Jewell C (2018) Modular control of innate immune signaling using self-assembly of immune signals.

77. Li X, Wang X, Ito A (2018) Tailoring inorganic nanoadjuvants towards next-generation vaccines. Chemical Society Reviews. 

(C) This work is licensed under Creative BY DOI: 10.19080/IJCSMB.2019.05.555671

\section{Your next submission with Juniper Publishers} will reach you the below assets

- Quality Editorial service

- Swift Peer Review

- Reprints availability

- E-prints Service

- Manuscript Podcast for convenient understanding

- Global attainment for your research

- Manuscript accessibility in different formats ( Pdf, E-pub, Full Text, Audio)

- Unceasing customer service

Track the below URL for one-step submission https://juniperpublishers.com/online-submission.php 